\title{
Spatial and Temporal Variations of Climate in Europe
}

\author{
Vladimir Kossobokov ${ }^{1,2}$, Jean-Louis Le Mouël' ${ }^{2}$, Claude Allègre ${ }^{2}$ \\ ${ }^{1}$ Institute of Earthquake Prediction Theory and Mathematical Geophysics, Russian Academy of Sciences, Moscow, Russia \\ ${ }^{2}$ Institut de Physique du Globe de Paris, Paris, France \\ Email: volodya@mitp.ru
}

Received July 4, 2012; revised August 7, 2012; accepted August 16, 2012

\begin{abstract}
Temperature series of the original individual measurements of the minimum and maximum daily temperatures from 24 stations located in different regions of Europe are considered with the objective of studying the stability or the variability of the "climate" in time and space. The patterns of the temperature statistics, the shapes of probability density functions, in particular, at different places and times allow comparisons based on the Kolmogorov-Smirnov test, the Shannon entropy, and cluster analysis, used separately or in combination for the purposes of quantitative climate classification.
\end{abstract}

Keywords: Daily Air Temperature; Climate; Classification; Empirical Distribution Function; Entropy; Cluster Analysis

\section{Introduction}

In two recent papers, we analyzed the longest temperature series in Europe (i.e., Prague, Bologna, and Uccle) available from the European Climate Assessment and Dataset [1]. The two former papers focused on the investigation of a solar effect on temperature series [2,3]. In the present paper we consider the temperature series from 24 stations located in different regions of Europe with the objective of studying the stability or the variability of the "climate" in time and space. For that, instead of considering series of temporal averages like, e.g., the series of monthly temperatures of the Northern Hemisphere, or of Central England, etc., we make use in full of the original individual measurements of the minimum and maximum daily temperatures and compare statistics of their distributions at different places and times.

\section{The Data}

We use the data set of the daily air temperature observations over more than a hundred years (in one case, more than two hundred years) published in 2007 by the European Climate Assessment and Data Set, ECA\&D. More precisely, we have extracted from ECA\&D the long series of minimum and maximum temperatures $\left(\mathrm{TN}=\mathrm{T}_{\min }\right.$ and $\mathrm{TX}=\mathrm{T}_{\max }$, respectively) at stations that sample different climatic regions of Europe. We did not retain the very long series of Central England [4] since we chose using non-blended data. The list of the selected 24 stations (ordered from $\mathrm{W}$ to $\mathrm{E}$ ), with their coordinates (latitude and longitude) and length of temperature series, are given in Table 1; their geographical distribution, along with climate classification, is shown in Figure 1.

We essentially compute and plot the empirical probability functions $\left(p f^{\prime} s\right), F_{i}(\tau)$, and probability density (distribution) functions $\left(p d f^{\prime} \mathrm{s}\right), f_{i}(\tau)$, of the different series $\mathrm{T}$ over different time intervals $Y_{i}=\left(y_{i+1}, y_{i}\right)$, where $y_{i}$ $-y_{i+1}=\Delta y$ years. By definition, for a given time interval, $F_{i}(\tau)$ and $f_{i}(\tau)$ are the ratios of the number of values from the temperature intervals $\mathrm{T} \leq \tau$ and $\mathrm{T} \leq \tau<\tau+\Delta \tau$ to the total number of values $\mathrm{T}$, respectively. Of course $p f$ 's and

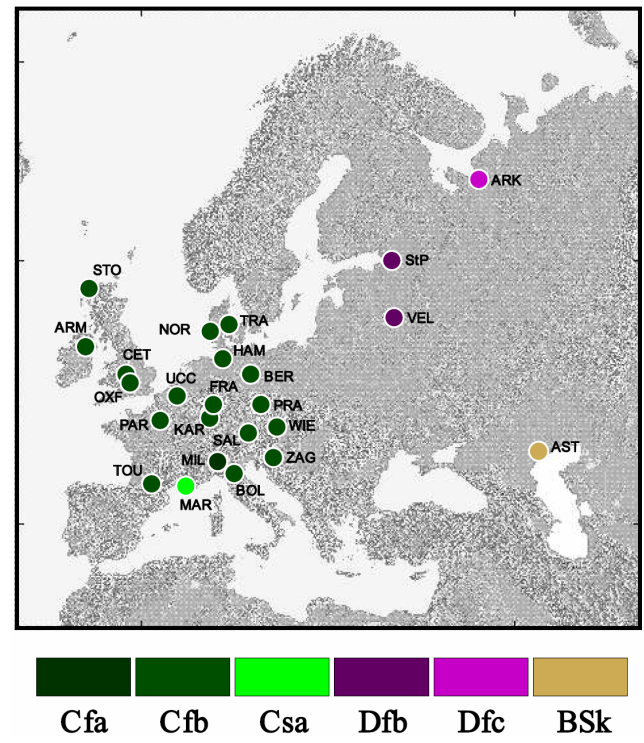

Figure 1. Geographical location of the 24 European stations with the daily air minimum and maximum temperature observations over more than a hundred years. Each location is color-coded in respect to the Köppen-Geiger climate classes [10] listed in Table 1. 
Table 1. Geographical coordinates and the Köppen-Geiger climate class [10] of the 24 stations from ECA\&D and the corresponding periods of the temperature series.

\begin{tabular}{|c|c|c|c|c|c|c|}
\hline Station name & Abr & Class & Latitude, ${ }^{\circ} \mathbf{N}$ & Longitude, ${ }^{\circ} \mathrm{E}$ & Start & End \\
\hline Armagh (UK) & ARM & $\mathrm{Cfb}$ & 54.350 & -6.650 & 1865 & 2001 \\
\hline Stornoway Airport (UK) & STO & $\mathrm{Cfb}$ & 58.217 & -6.317 & 1873 & 2001 \\
\hline Central England (UK) & CET & $\mathrm{Cfb}$ & 52.417 & -1.833 & 1881 & 2001 \\
\hline Oxford (UK) & OXF & $\mathrm{Cfb}$ & 51.767 & -1.267 & 1853 & 2001 \\
\hline Toulouse Blagnac (France) & TOU & $\mathrm{Cfb}$ & 43.623 & 1.378 & 1878 & 2005 \\
\hline Paris Montsouris (France) & PAR & $\mathrm{Cfb}$ & 48.823 & 2.337 & 1900 & 2001 \\
\hline Uccle (Belgium) & $\mathrm{UCC}$ & $\mathrm{Cfb}$ & 50.800 & 4.350 & 1833 & 2001 \\
\hline Marseille Longchamp (France) & MAR & Csa & 43.305 & 5.397 & 1900 & 2001 \\
\hline Karlsruhe (Germany) & KAR & $\mathrm{Cfb}$ & 49.017 & 8.383 & 1876 & 2001 \\
\hline Nordby (Denmark) & NOR & $\mathrm{Cfb}$ & 55.450 & 8.400 & 1874 & 2003 \\
\hline Frankfurt (Germany) & FRA & $\mathrm{Cfb}$ & 50.117 & 8.667 & 1870 & 2001 \\
\hline Milan (Italy) ${ }^{*}$ & MIL & $\mathrm{Cfa}$ & 45.472 & 9.189 & 1838 & 2008 \\
\hline Hamburg Fuhlsbüttel (Germany) & HAM & $\mathrm{Cfb}$ & 53.550 & 9.967 & 1879 & 2001 \\
\hline Tranebjerg (Denmark) & TRA & $\mathrm{Cfb}$ & 55.850 & 10.600 & 1872 & 2003 \\
\hline Bologna (Italy) & BOL & $\mathrm{Cfb}$ & 44.483 & 11.250 & 1814 & 2001 \\
\hline Salzburg (Austria) & SAL & $\mathrm{Cfb}$ & 47.800 & 13.000 & 1874 & 2004 \\
\hline Berlin (Germany) & BER & $\mathrm{Cfb}$ & 52.450 & 13.300 & 1876 & 2001 \\
\hline Praha Klementinum (Czech Republic) & PRA & $\mathrm{Cfb}$ & 50.091 & 14.419 & 1775 & 2005 \\
\hline Zagreb Gric (Croatia) & ZAG & $\mathrm{Cfb}$ & 45.817 & 15.978 & 1881 & 2001 \\
\hline Wien (Austria) & WIE & $\mathrm{Cfb}$ & 48.233 & 16.350 & 1852 & 2004 \\
\hline St Petersburg (Russian Federation) & StP & $\mathrm{Dfb}$ & 59.967 & 30.300 & 1881 & 2003 \\
\hline Velikie Lukie (Russian Federation) & VEL & $\mathrm{Dfb}$ & 56.350 & 30.617 & 1881 & 2003 \\
\hline Arkhangelsk (Russian federation) & ARK & Dfc & 64.500 & 40.733 & 1881 & 2003 \\
\hline Astrakhan (Russian Federation) & AST & BSk & 46.283 & 46.283 & 1881 & 2003 \\
\hline
\end{tabular}

Notes: (a) Cfa-warm temperate climate, fully humid, with hot summer; $\mathrm{Cfb}$ - warm temperate climate, fully humid, with warm summer; Csa-warm temperate climate with dry and hot summer; Dfb-snow climate, fully humid, with warm summer; Dfc — snow climate, fully humid, with cool summer and cold winter; BSk - cold steppe climate; (b) The two temperature series for Milan (ECA\&D source IDs 105,247 for $T_{\min }$ and 105248 for $T_{\max }$ both starting in 1763 ) look suspiciously coherent, possibly, man-made before 1838 .

$p d f$ 's are of classical use in climatology (see e.g. [5] and references therein).

An extensive list of indices has been proposed to characterize the climate at a given station from temperature, pressure, precipitation, etc recordings [6]. These are of course very useful. Nevertheless, we think that the patterns of the temperature statistics (the shapes of $p d f$ 's, in particular) can provide much additional information allowing to characterize the "climate" at a given station at a single glance.

Note: We take the ECA\&D non-blended series as they are, without submitting them to any kind of "homogeni- zation" process. We think that such a process can hardly be applied to the data without a deep knowledge of the history of observations, which is particularly difficult to achieve for the old stations with long series of records. We prefer to trust the local observers whose diligent efforts on collecting and archiving the existing data is invaluable. Blind "homogenization" to a pre-conceptual model may lead to reject most of the data [7]: e.g., the homogeneity checking results for the 1901-2009 period (the ECA\&D file TEMP_19012009_homogeneity.txt) found only 6 "useful", 1 "doubtful", and 118 "suspect" out of 122 stations. 
It is well known that some stations, in particular, those installed in sites now included in a big city, can be affected by a heat island effect (e.g. [8]). We will point out some of them in the analysis.

\section{The Empirical Distribution Functions}

Let us start with taking all the daily minimum and maximum temperatures observed at the station of Bologna (BOL), ranked according to the calendar day and stacked. We consider successively the periods 1814-1970 and 1971-2000 (Figures 2(a) and (b)). The original readings of temperatures corresponding to the two periods for both $\mathrm{T}_{\min }$ (minimum daily temperature) and $\mathrm{T}_{\max }$ (maximum daily temperature) are in good agreement. Nevertheless, when averaging is applied, a slight increase in $\mathrm{T}_{\min }$ and $\mathrm{T}_{\max }$ for the months of December, January, February, and March, is noticeable (of the order of $1^{\circ} \mathrm{C}$ $2^{\circ} \mathrm{C}$ ). This might reflect the warming in Europe, in the last decade of the 20th century noted by Le Mouël et al. [9] to start actually in 1987.

We then compute and plot $p f^{\prime}$ s and $p d f^{\prime} \mathrm{s}$ of $\mathrm{T}_{\min }$ and

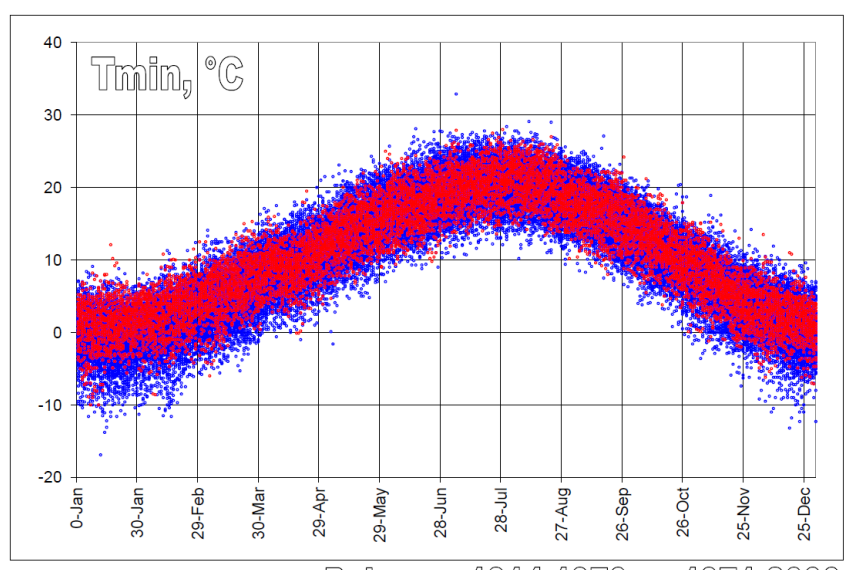

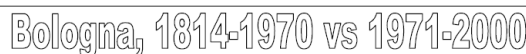

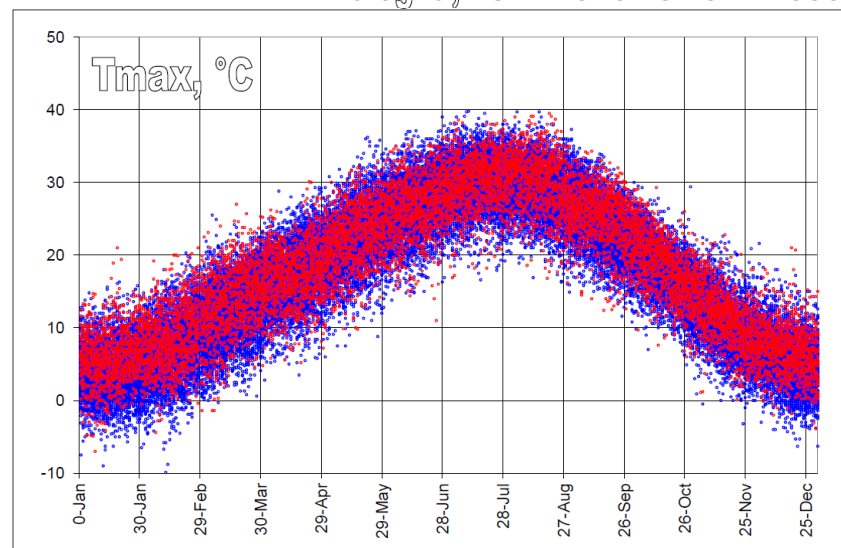

(a)
$\mathrm{T}_{\max }$ with uniform bins $\Delta \tau=1^{\circ} \mathrm{C}$ at every station over successive periods of 30 years (and the remainder) depending on the length of the series in order to examine their long term evolution. Figures 3-5 illustrate the results to follow.

First of all, we observe the striking stability of $p f$ 's and $p d f$ 's over time in all stations but those affected by a heat island effect: the $\mathrm{T}_{\min }$ and $\mathrm{T}_{\max }$ curves vary only slightly over a hundred years or more. However, the comparison of the temperature distributions derived from different 30-year intervals shows that these are hardly drawn from the same distribution. Specifically, Figure 5 shows that for the two most recent intervals the difference between empirical probability distributions, $F_{l}(\tau)-F_{0}(\tau)$, may exceed $+6 \%\left(\mathrm{~T}_{\min }\right.$ at TRA and $\mathrm{T}_{\max }$ at MIL) indicating evident "warming" or go below $-5 \%\left(\mathrm{~T}_{\max }\right.$ at UCC) indicating evident "cooling". Table 2 shows the results of the comparison of empirical distributions for each pair of time intervals at Prague (PRA), i.e. the longest ECA\&D series of $\mathrm{T}_{\min }$ and $\mathrm{T}_{\max }$. The two sample KolmogorovSmirnov statistic $\lambda_{\mathrm{K}-\mathrm{S}}(D, n, m)=[n m /(n+m)]^{1 / 2} D$, where

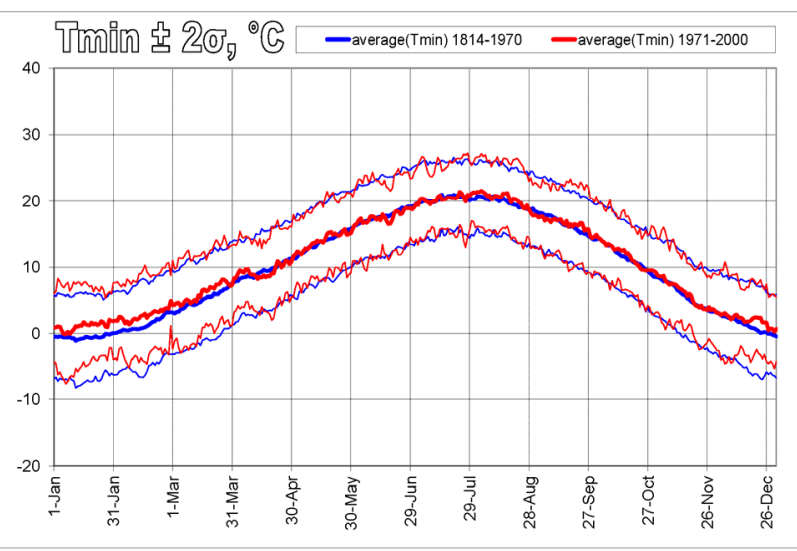

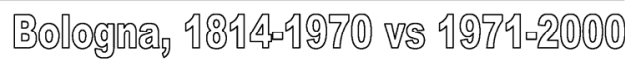

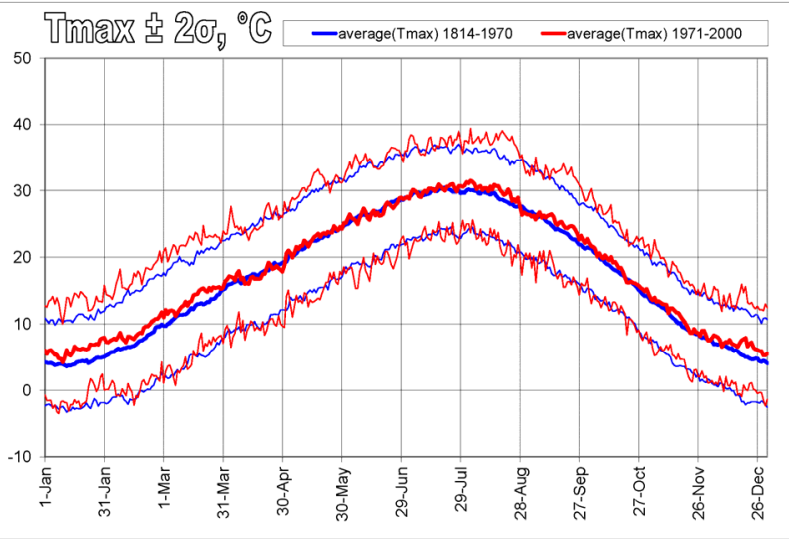

(b)

Figure 2. The daily minimum (left) and maximum (right) temperatures (a) and their averages (b) observed at Bologna on the calendar day in 1814-1970 (blue) and 1971-2000 (red). The graphs of averages are supplied with the plus/minus two standard deviation curves. 

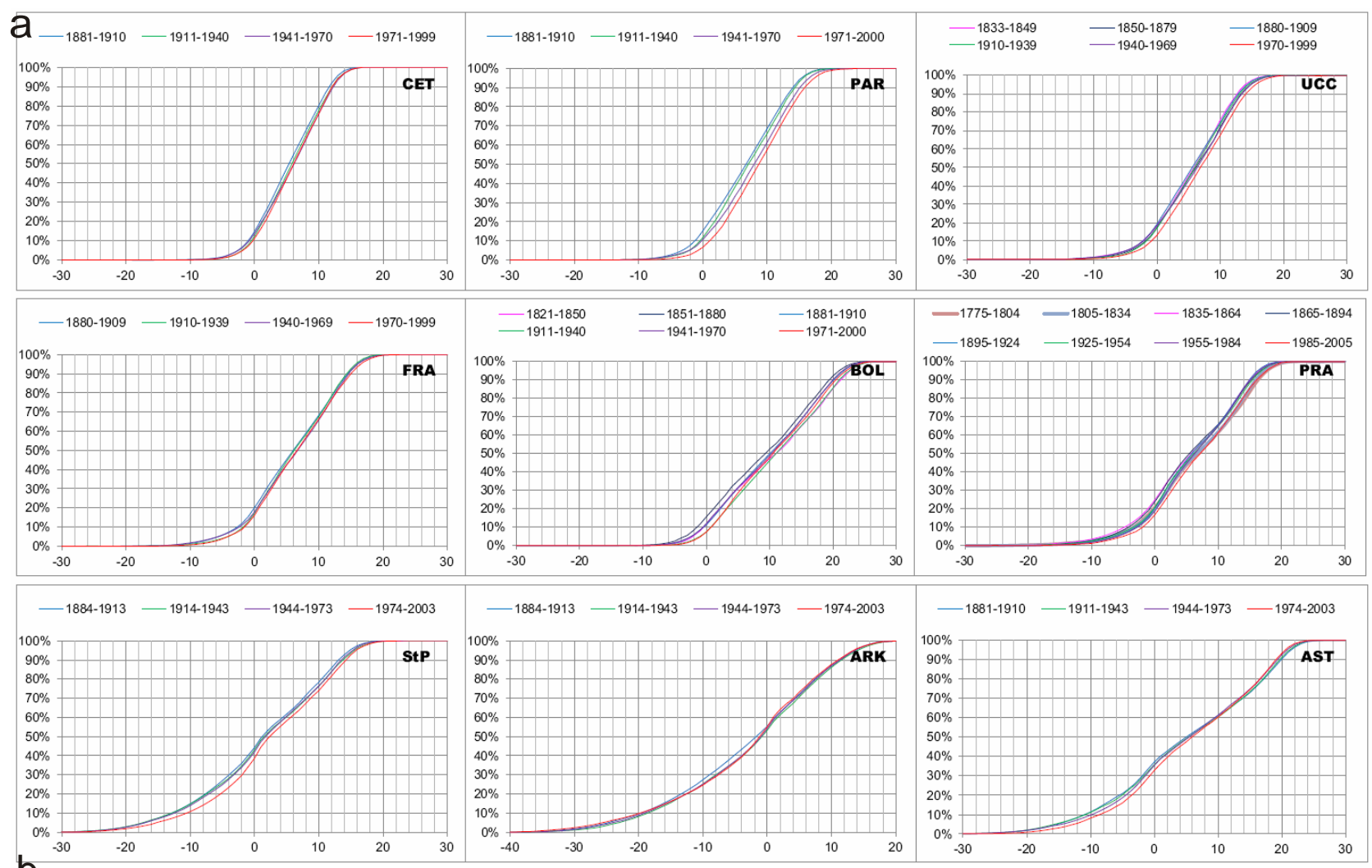

b
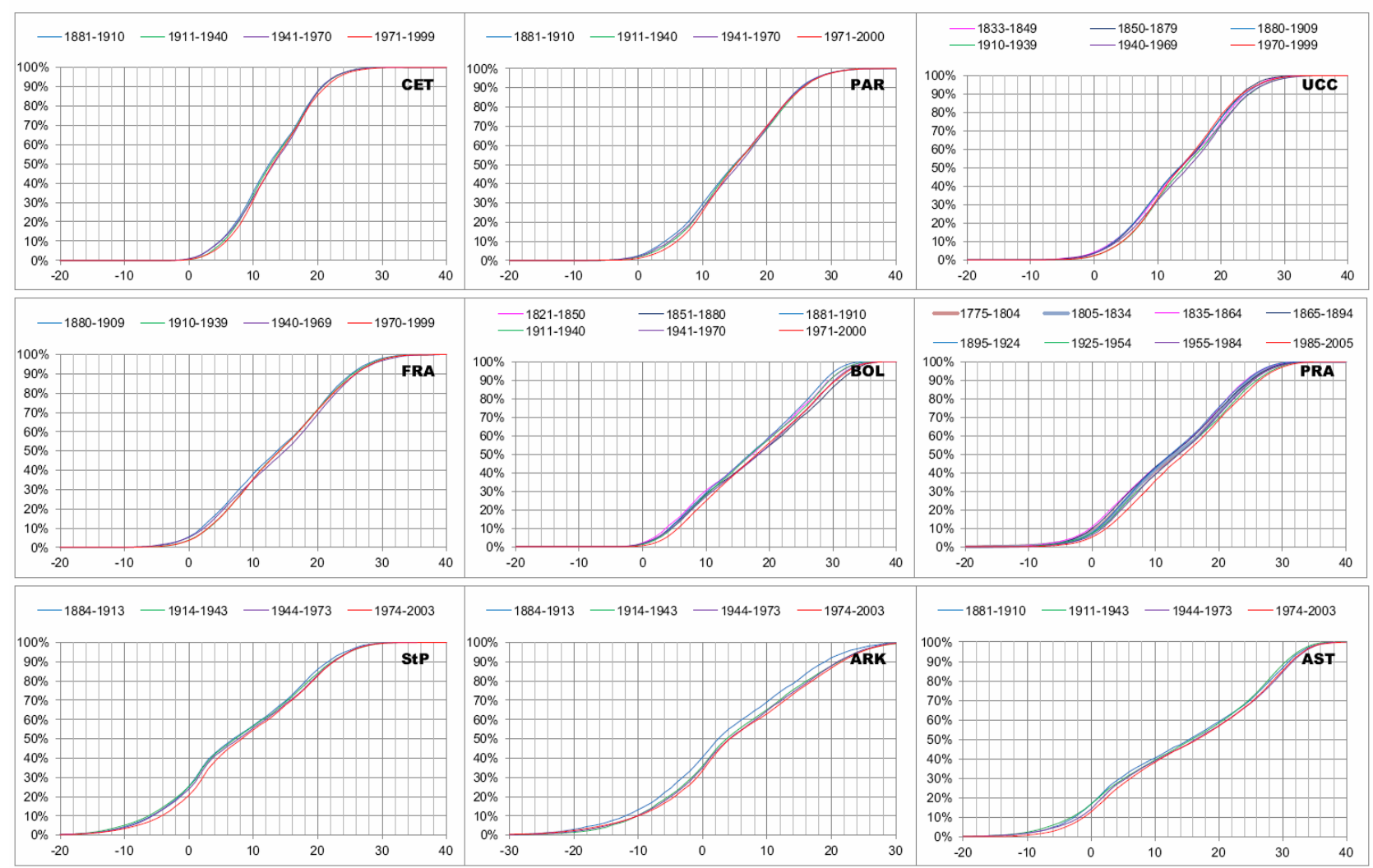

Figure 3. The empirical probability (distribution) functions, $F(\tau)$, of the minimum (a) and maximum (b) temperatures, $T_{\min }$ and $T_{\max }$ over different time intervals. Note: the complete set of plots for the 24 European stations is given in Supplement. 

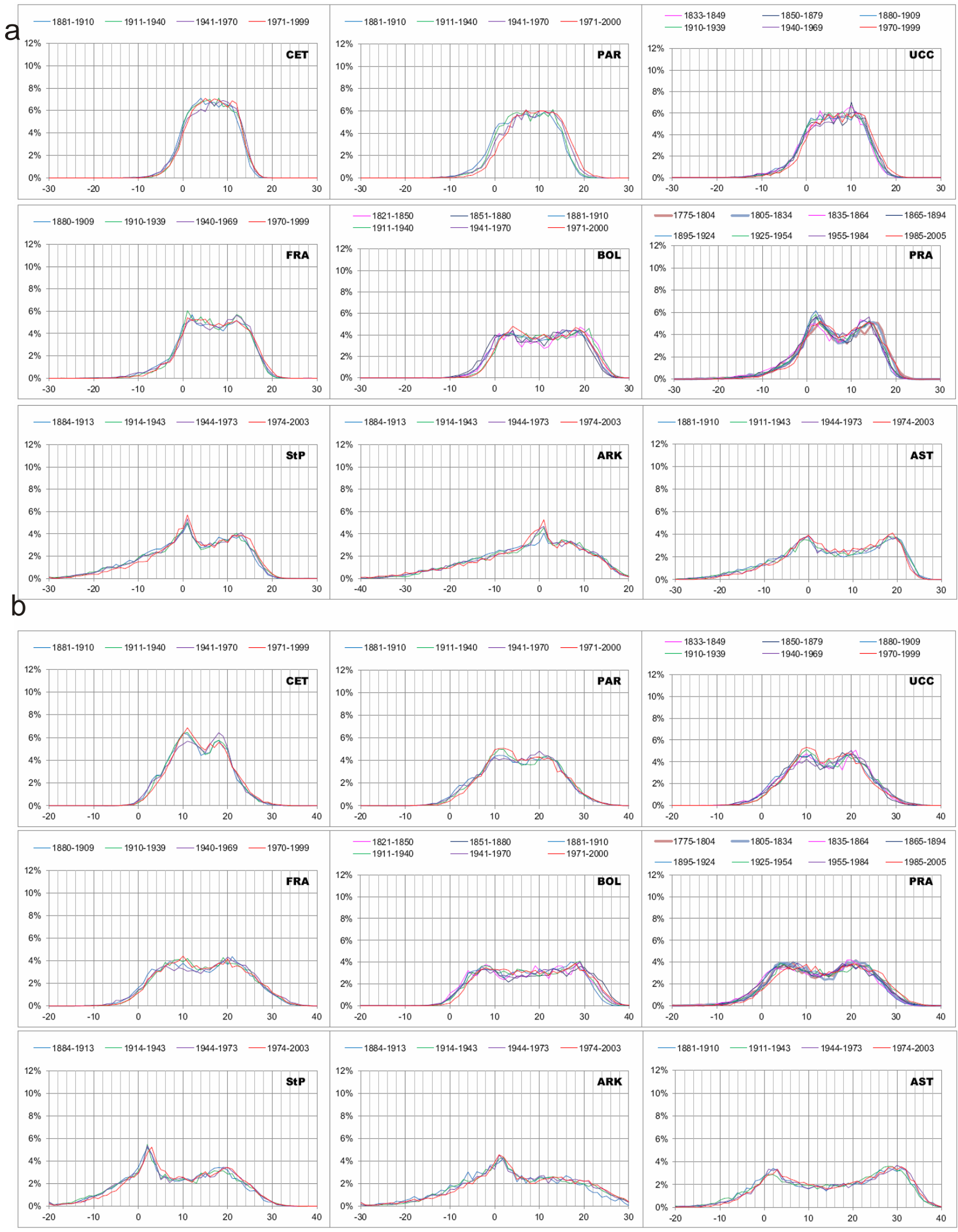

Figure 4. The empirical probability density (distribution) functions, $f(\tau)$, of the minimum (a) and maximum (b) temperatures, $T_{\min }$ and $T_{\max }$, over different time intervals. Note: the complete set of plots for the 24 European stations is given in Supplement. 

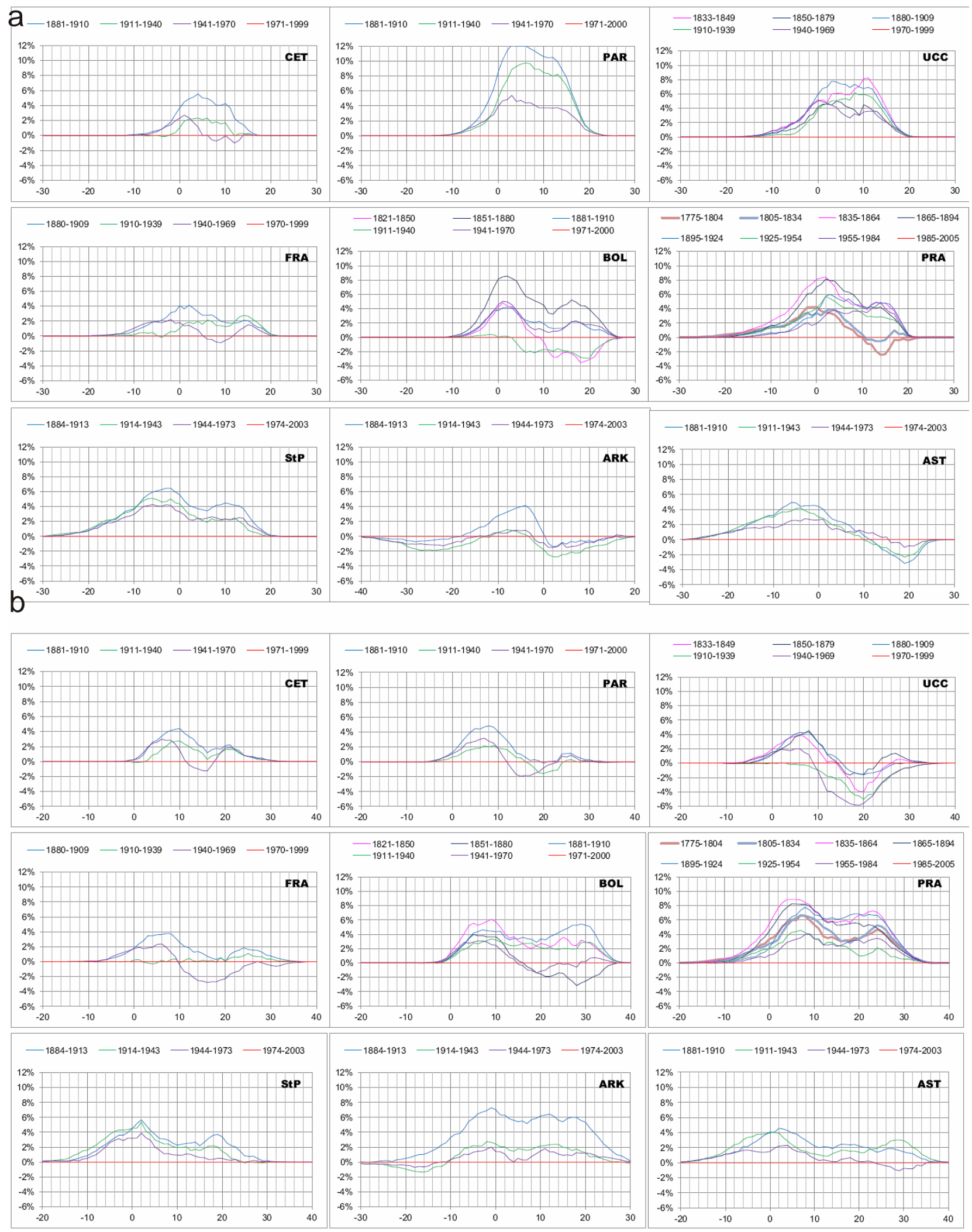

Figure 5. The difference between the empirical probability functions, $F(\tau)$, of the minimum (a) and maximum (b) temperatures, $T_{\min }$ and $T_{\max }$, over different time intervals and the recent most one, $D_{k}(\tau)=F_{k}(\tau)-F_{0}(\tau)$. Note: $D_{k}(\tau)>0$ indicates relative "warming", while $D_{k}(\tau)<0$ indicates relative "cooling". The complete set of plots for the 24 European stations is given in Supplement. 
Table 2. The K-S test comparison of 30-year intervals at Prague.

\begin{tabular}{|c|c|c|c|c|c|c|c|c|}
\hline \multicolumn{9}{|c|}{$\mathrm{T}_{\min }$ at Prague (PRAHA-KLEMENTINUM; source-ID: 100079). } \\
\hline & $1775-1804$ & $1805-1834$ & $1835-1864$ & $1865-1894$ & $1895-1924$ & 1925-1954 & $1955-1984$ & 1985-2005.VI \\
\hline & 1 & 2 & 3 & 4 & 5 & 6 & 7 & 8 \\
\hline 1 & 10957 & -1.466 & -5.371 & -4.945 & -5.350 & -3.965 & -5.432 & -1.636 \\
\hline 2 & 0.865 & 10957 & -5.715 & -4.968 & -5.627 & -3.582 & -5.657 & -0.548 \\
\hline 3 & 0.142 & 0.048 & 10958 & -1.105 & -0.321 & -0.007 & -0.061 & 0.000 \\
\hline 4 & 0.263 & 0.182 & 0.958 & 10957 & -1.094 & -0.095 & -0.487 & -0.012 \\
\hline 5 & 1.108 & 0.994 & 3.451 & 2.574 & 10957 & -0.676 & -0.082 & -0.002 \\
\hline 6 & 0.574 & 0.325 & 2.998 & 2.195 & 1.527 & 10957 & -1.467 & 0.000 \\
\hline 7 & 1.879 & 1.530 & 4.593 & 3.791 & 1.948 & 1.941 & 10958 & -0.020 \\
\hline 8 & 2.819 & 4.108 & 5.609 & 5.417 & 3.977 & 3.814 & 3.247 & 7425 \\
\hline \multicolumn{9}{|c|}{ Tmax at Prague (PRAHA-KLEMENTINUM; source-ID: 100081). } \\
\hline & $1775-1804$ & $1805-1834$ & $1835-1864$ & $1865-1894$ & $1895-1924$ & $1925-1954$ & $1955-1984$ & 1985-2005.VI \\
\hline $\mathrm{TX}$ & 1 & 2 & 3 & 4 & 5 & 6 & 7 & 8 \\
\hline 1 & 10957 & -0.946 & -2.573 & -1.709 & -2.608 & 0.000 & 0.000 & 0.000 \\
\hline 2 & 0.703 & 10957 & -4.632 & -3.191 & -4.089 & 0.000 & -0.280 & 0.000 \\
\hline 3 & 0.115 & 0.010 & 10958 & -0.077 & -0.795 & 0.000 & 0.000 & 0.000 \\
\hline 4 & 0.277 & 0.869 & 1.656 & 10957 & -1.344 & -0.047 & -0.007 & 0.000 \\
\hline 5 & 0.912 & 1.146 & 2.620 & 1.756 & 10957 & -0.405 & -0.020 & -0.006 \\
\hline 6 & 2.027 & 3.468 & 4.345 & 3.344 & 4.344 & 10957 & -1.630 & -0.006 \\
\hline 7 & 2.326 & 3.280 & 4.526 & 3.811 & 2.873 & 0.872 & 10958 & -0.019 \\
\hline 8 & 4.421 & 6.946 & 5.896 & 5.503 & 5.166 & 3.037 & 2.710 & 7425 \\
\hline
\end{tabular}

Note: the sample size of a 30 -year interval is given on the diagonal, while the values of $\lambda_{\mathrm{KS}-}$ and $\lambda_{\mathrm{KS}+}$ are put above and below the diagonal, respectively. The $\lambda_{\mathrm{KS}-}$ and $\lambda_{\mathrm{KS}}+$ above 1.36 in absolute value are highlighted (see text).

$D=\max \left|F_{i}(\tau)-F_{j}(\tau)\right|$ is the maximum value of the absolute difference between the empirical distributions $F_{i}(\tau)$ and $F_{j}(\tau)$ of the two samples ( $\tau$ covers the entire range of temperature index $\mathrm{T}=\mathrm{T}_{\min }$ or $\mathrm{T}_{\max }$ ), whose sizes are $n$ and $m$ respectively. Table 2 summarizes the test results in terms of $\lambda_{\mathrm{K}-\mathrm{S}}$, leaving the issue of statistical significance in terms of probability to more delicate testing against randomized data [3]. For the purpose of further comparison, we distinguish the two possible outcomes of the Kolmogorov-Smirnov test by providing in Table 2 both extremes, i.e. the minimum $\lambda_{\mathrm{K}-\mathrm{s}-}$ and maximum $\lambda_{\mathrm{K}-\mathrm{S}+}$ of $\left(F_{i}(\tau)-F_{j}(\tau)\right)$. We see that the maximum of the absolute values of $\lambda_{\mathrm{K}-\mathrm{S}-}$ and $\lambda_{\mathrm{K}-\mathrm{S}+}$ are above the standard critical value of 1.36 (highlighted) for all pairs of intervals considered for Prague. This is a clear indication of intrinsic variability of local "climate", however quite small at the time scale of a few decades, which in detail analysis requires an accurate application of specially designed problem oriented statistical tools (e.g. [3]). In this respect it is notable that for Bologna (Figure 5, BOL) the most recent interval (1971-2000), at the same time, is "cooler" in terms of $\mathrm{T}_{\min }$ and "warmer" in terms of $\mathrm{T}_{\max }$ than in the same one 30-year period (1911-1940) in the past. There are also cases of a Z-shape differences of $p f^{\prime} s$ with a "warming" at low temperatures and "cooling" at high temperatures, like for $\mathrm{T}_{\max }$ in Paris and Uccle (Figure 5(b), PAR and UCC).

On the contrary, the shape patterns of $p f^{\prime}$ 's and $p d f^{\prime}$ s change quite significantly from one station to the other (Figures 3 and 4). The sets of diagrams obtained for all 24 stations are self-explanatory and provide a lot of synthetic information on the European temperatures in space and time. In particular, we will show now that the shape patterns of $p f$ 's and $p d f$ 's can be organized into three distinct groups corresponding to the different regions of Europe with different climates (Figure 1).

a) The 4 stations located in the Russian Federation (Arkhangelsk, St Petersburg, Velikie Lukie, Astrakhan) 
share the trait of having a harsh continental climate.

In Arkhangelsk, situated close to the polar circle, the winters are very long and cold and the summers are short and cool or moderately warm. Over the century, the than probability curves ( $p f^{\prime}$ 's) show an overall warming of less $2^{\circ} \mathrm{C}$ for negative $\mathrm{T}_{\min }$ and about $2^{\circ} \mathrm{C}$ for almost the entire range of $\mathrm{T}_{\max }$ (Figures 3(a) and (b)). Note that the over- all warming is essentially attributed to transition from 1884-1913 to 1914-1943, while the $p f$ 's for the remaining three intervals are much closer to each other for both $T_{\min }$ and $\mathrm{T}_{\max }$. The probability density curves for $\mathrm{T}_{\max }$ and $\mathrm{T}_{\min }$ (Figures 4(a) and (b)) exhibit a peak around $0^{\circ} \mathrm{C}$, with a long heavy tail towards colder temperatures and a shoulder at higher temperatures $\left(3^{\circ} \mathrm{C}\right.$ to $10^{\circ} \mathrm{C}$ for $\mathrm{T}_{\min }$ and
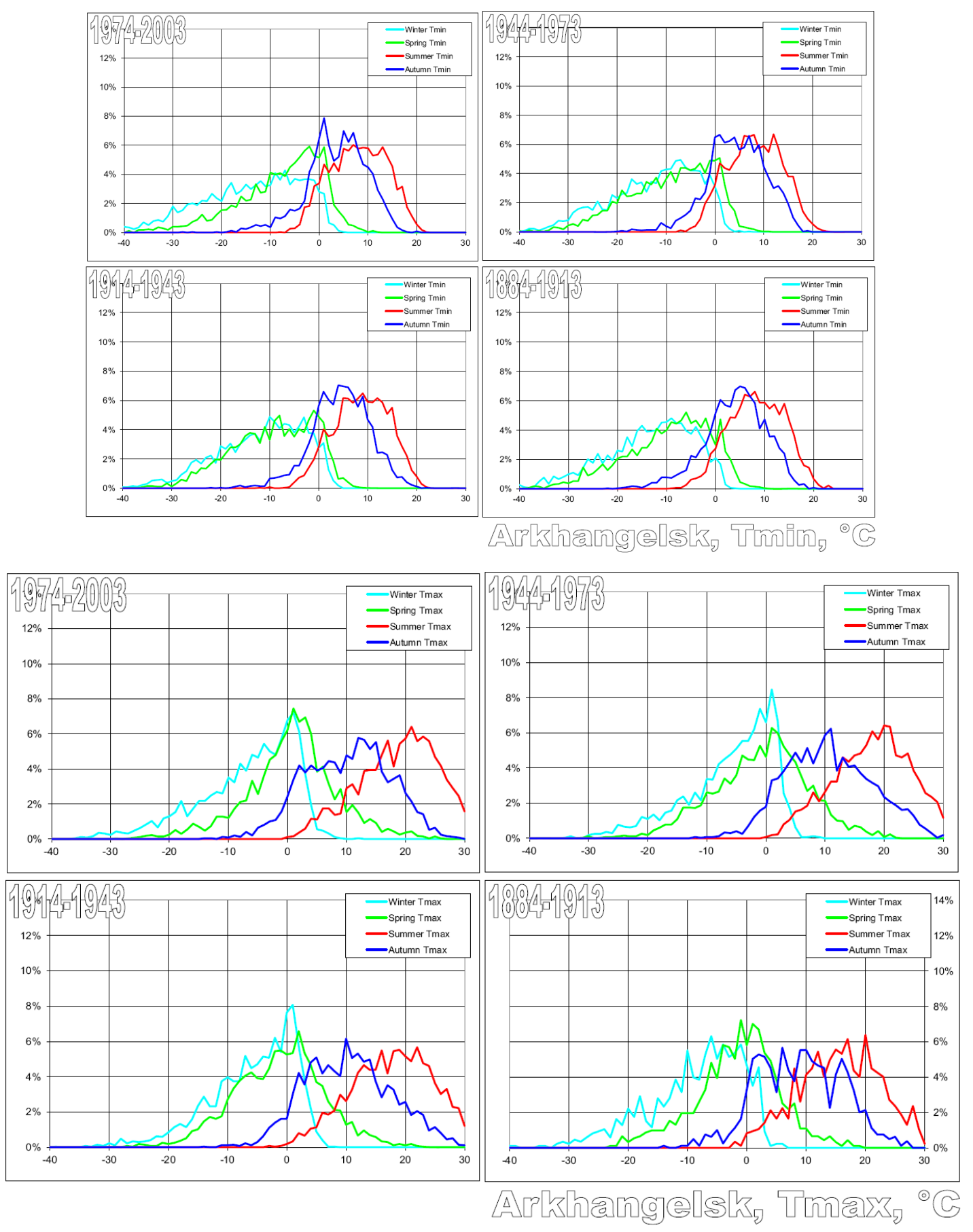

Figure 6. The four-seasons' probability density curves, $f(\tau)$, for $T_{\min }(a)$ and $T_{\max }(b)$ in Arkhangelsk. Note: the four seasons are defined as follows: winter $=$ November 7-February 5, spring $=$ February 6-May 7, summer $=$ May 8-August 7, August 8-November 6. 
$5^{\circ} \mathrm{C}$ to $20^{\circ} \mathrm{C}$ for $\left.\mathrm{T}_{\max }\right)$ (Figures 3(c) and (d)).

Probability density curves were drawn separately for the four seasons (Figure 6). The $\mathrm{T}_{\min }$ and $\mathrm{T}_{\max }$ curves for winter and spring are similar and they both exhibit a long heavy tail towards lower temperatures, probably due to the persistence of the snow cover. The curves for autumn and summer are also similar after a translation. The high proportion of $\mathrm{T}_{\min }$ for autumn and summer and $\mathrm{T}_{\max }$ for winter and spring close to $0^{\circ} \mathrm{C}$ accounts for the strong peak in the stacked yearly curves.

St Petersburg and Velikie Lukie are both in a snow zone of continental climate, but more to the south than Arkhangelsk. Although the temperatures are less cold than in Arkhangelsk, the yearly curves (Figure 4) still exhibit a strong peak around $0^{\circ} \mathrm{C}$ and a long tail towards colder temperatures. However, there are more warm days in autumn and summer and the curves exhibit an uplifted shoulder with a distinct peak above $10^{\circ} \mathrm{C}$ for $\mathrm{T}_{\min }$ and up to $20^{\circ} \mathrm{C}$ for $\mathrm{T}_{\max }$.

In Astrakhan, one of the driest cities in Europe, on the northern shore of the Caspian Sea, the steppe climate is continental and the $p d f$ curves exhibit again a long heavy tail towards lower temperatures. The presence of two well-identified peaks at temperatures around $0^{\circ} \mathrm{C}$ and $20^{\circ} \mathrm{C}$ for $\mathrm{T}_{\min }$ (Figure 4(a) and $30^{\circ} \mathrm{C}$ for $\mathrm{T}_{\max }$ (Figure 4(b))

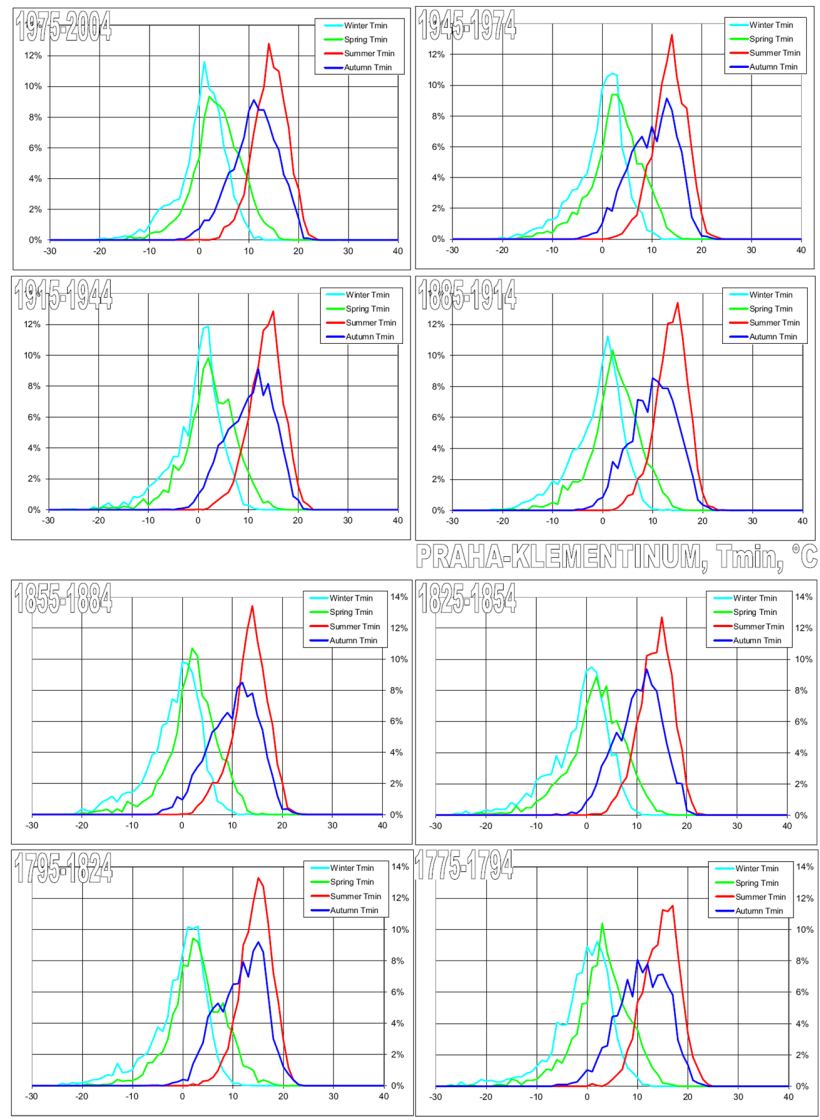

accounts for cold winters and hot summers much warmer than in St Petersburg or Velikie Lukie.

b) In central Europe (Berlin, Hamburg, Prague, Frankfurt, Karlsruhe, Wien, Salzburg, Zagreb, Milan, Bologna), the climate is mild continental with no dry season, not as harsh as in Russia.

A typical example is Prague (Figure 7) where $T_{\min }$ and $\mathrm{T}_{\max }$ temperatures have been observed since 1775 . The $\mathrm{T}_{\min }$ and $\mathrm{T}_{\max } p d f$ 's (Figure 4) for the periods 1775-1804, 1805-1834, 1835-1864, 1865-1894, 1895-1924, 19251954, 1955-1984, and 1985-2005, are not very different, they exhibit two distinct peaks above 0 and below $15^{\circ} \mathrm{C}$ for $\mathrm{T}_{\min }$ and around $5^{\circ} \mathrm{C}$ and $20^{\circ} \mathrm{C}$ for $\mathrm{T}_{\max }$. The $\mathrm{T}_{\min }$ curves for spring and autumn are not far apart from those for winter and summer, respectively (Figure 7(a)), but the $\mathrm{T}_{\max }$ curves for spring and summer are more clearly shifted towards temperatures higher by up to $10^{\circ} \mathrm{C}$ with respect to those for winter and autumn (Figure 7(b)). Although of a character somewhat transitional to that of Western Europe, Karlsruhe, Frankfurt and Bologna (Figure 8) can be, for simplicity sake, put together with the stations of central Europe.

c) In Western Europe (Stornoway, Armagh, Central England, Oxford, Tranebjerg, Nordby, Uccle, Paris, Toulouse, Marseille), the climate is frankly oceanic, warm-

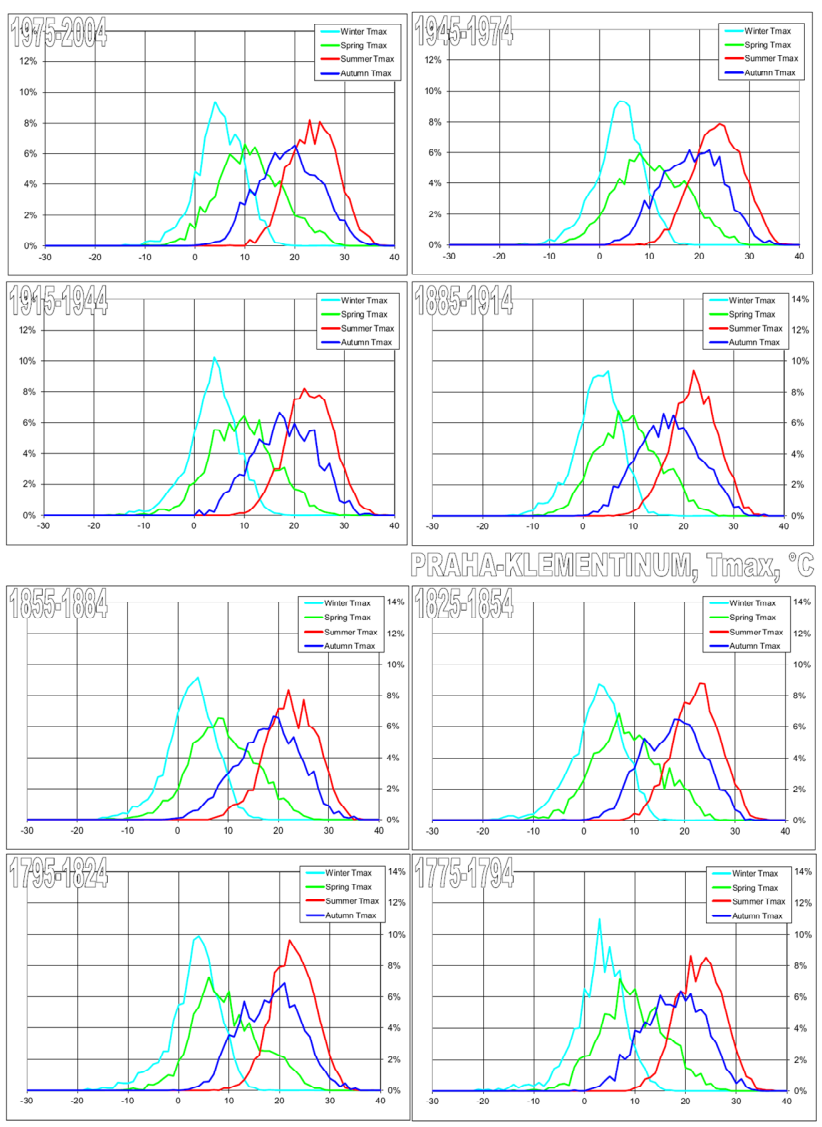

Figure 7. The four-seasons' probability density curves, $f(\tau)$, for $T_{\min }(a)$ and $T_{\max }(b)$ in Prague. Note: same as in Figure 6. 


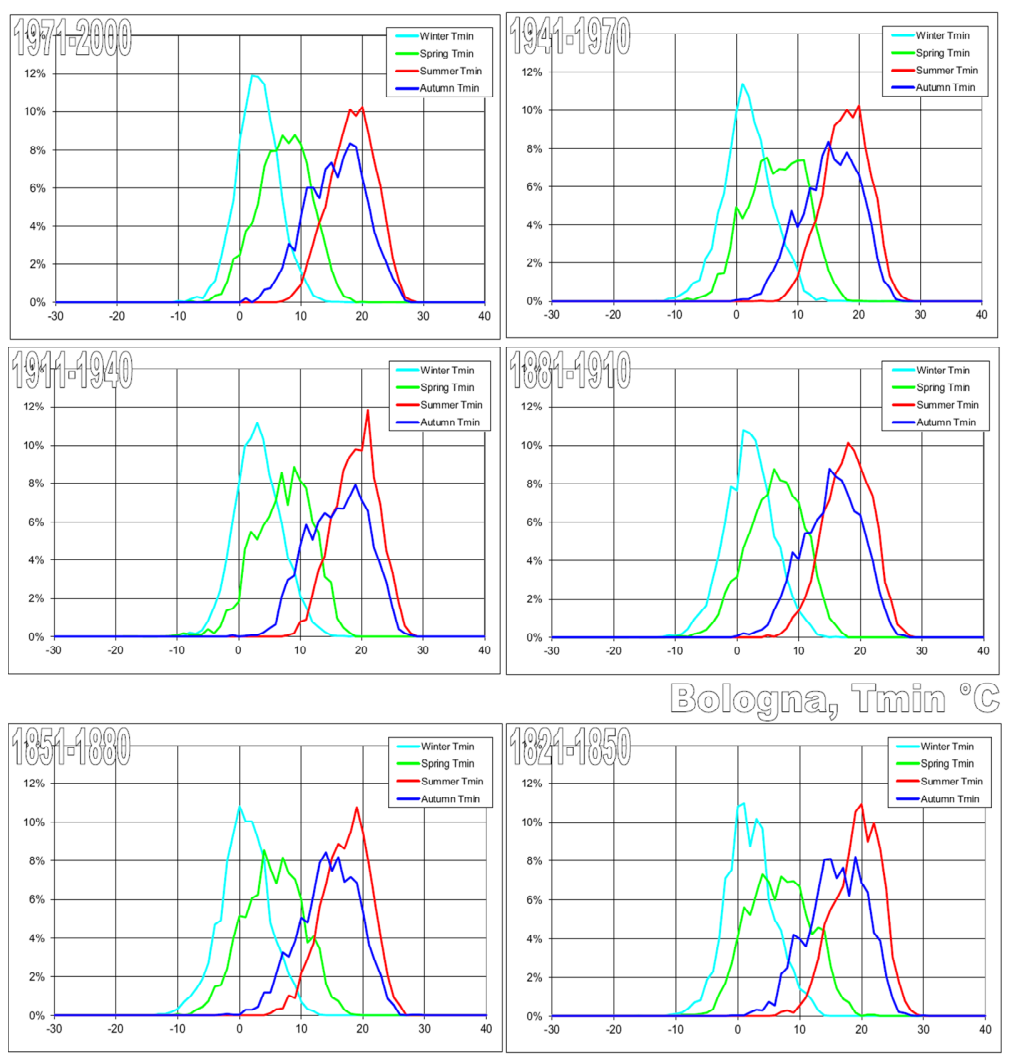

(a)
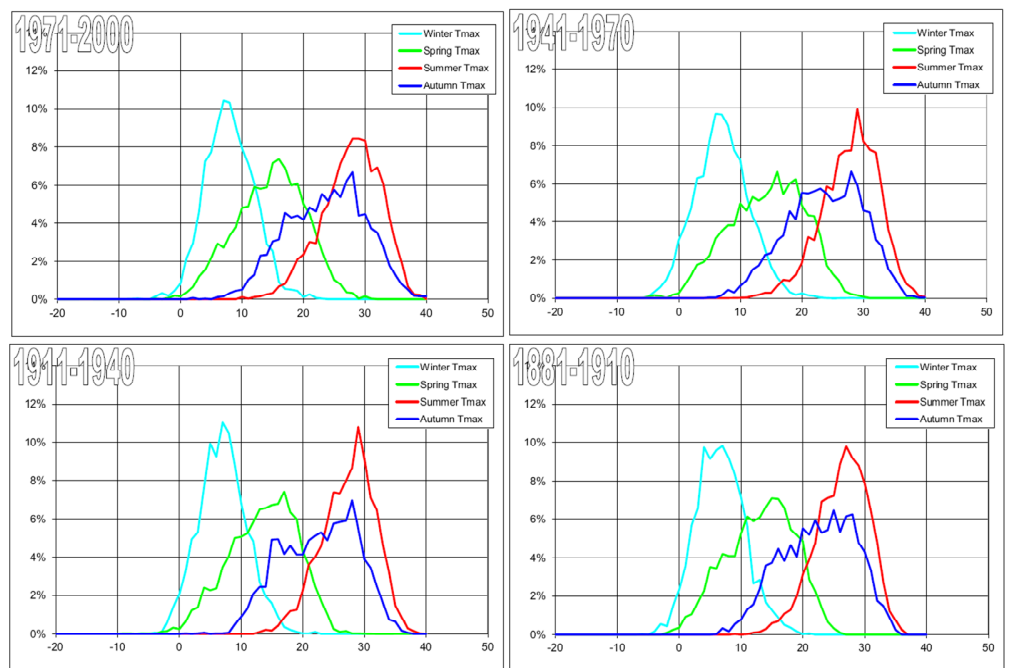

B)(0)
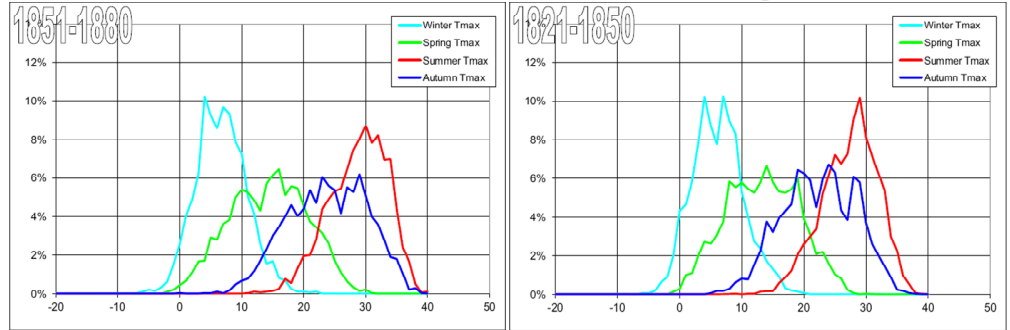

(b)

Figure 8. The four-seasons' probability density curves, $f(\tau)$, for $T_{\min }(a)$ and $T_{\max }(b)$ in Bologna. Note: same as in Figure 6. 
fully humid with warm summer, except for Marseille with dry and hot summer. The peaks of $p d f$ 's now over lap yielding a single wide peak at about $10^{\circ} \mathrm{C}$ for $\mathrm{T}_{\min }$ and an almost flat plateau from $10^{\circ} \mathrm{C}$ to above $20^{\circ} \mathrm{C}$ for $\mathrm{T}_{\text {max }}$ (Figure 4). A typical example is Paris.

\section{Temperature Changes}

From the comparison of repartition $p f$ and $p d f$ curves, it is possible to obtain an estimate of the average temperature changes over successive 30 years period, for the various stations. We just give a brief account of it.

a) At Arkhangelsk and St Petersburg (as already mentioned above for Arkhangelsk, Figure 3) the average $\mathrm{T}_{\max }$ is higher for about $2^{\circ} \mathrm{C}$ for the three 30 years periods starting in 1914, as compared with the period 1884-1913.

There is no significant difference between the periods 1914-1943, 1944-1973, 1974-2003. $\mathrm{T}_{\min }$ does not significantly vary from 1884 to 2003. Although somewhat less clearly, $\mathrm{T}_{\min }$ and $\mathrm{T}_{\max }$ at Velikie Lukie and Astrakhan exhibit a similar behavior.

b) At Prague (Praha-Klementium), there is no discernible difference between the 30-year period curves for $\mathrm{T}_{\max }$ starting in 1775 up to 1985 . The curve for 1985 2005 shows a temperature increase of about $1{ }^{\circ} \mathrm{C}$ or more. There is a slighter increase in $\mathrm{T}_{\min }$, moreover, the curves for 1775-1804 and 1805-1834 show up about the same or even higher temperatures in the upper quartiles of the distributions. The temperatures at Salzburg, Wien, Karlsruhe and Bologna behave approximately in the same way. At Nordby and Tranebjerg, although all the curves are somewhat bundled together, there may be a slight increase in both $\mathrm{T}_{\min }$ and $\mathrm{T}_{\max }$ over the last 30-year period.

At Zagreb, as well as at Berlin, and less clearly at Hamburg and Frankfurt, there is no discernible evolution of $\mathrm{T}_{\min }$ and $\mathrm{T}_{\max }$ since the 1880 's.

c) At the stations situated in the British Isles (Oxford, Central England, Armagh), except for the northern most one (Stornoway) there is practically no change of either $\mathrm{T}_{\max }$ or $\mathrm{T}_{\min }$ over the whole period 1853-1972, then, in the last interval 1973-2001) a small warming of about $0.5^{\circ} \mathrm{C}$ is observed (see Le Mouël et al., 2009).

d) At Uccle, Toulouse, and very clearly at Paris and Marseille, it is $T_{\min }$ that increases over the last 30 years, while $T_{\max }$ behaves differently-decreases for about $1{ }^{\circ} \mathrm{C}$ at Uccle, increases for about $1{ }^{\circ} \mathrm{C}$ at Toulouse, and does not change that much at Paris and Marseille. This could be attributed, at least partly, to a heat island effect, as the cities of Brussels (close to Uccle), Toulouse, Paris, and Marseille have considerably expanded in the last 30 years.

\section{Quantitative Climate Classifications}

We have identified above three climatic regions, for which the shape of the $p f$ and $p d f$ curves is similar: Eastern Europe, Central Europe, and Western Europe. We will now retrieve this classification, in its broad lines, through quantitative criteria.

Entropy is a measure of uncertainty or diversity of the system. It characterizes also the quantity of informationtaken in average - which is missing for knowing whether state $i$ (here a temperature in the interval from $T_{i}$ to $T_{i}+$ $\Delta T$ ) will be realized when only the $p d f$ is known. Specifically, we compute the Shannon's entropy $H$ defined as $H=-\Sigma p_{i} \ln p_{i}$, where $p_{i}$ is the probability density function, $i=1, \cdots, N$. The maximum $H=\ln N$ is reached for the uniform distribution $p_{i}=1 / N$ (for all $i$ ), therefore, for the sake of comparison, we use here normalized value $H^{*}=H / \ln N$ (i.e., the so-called, efficiency in information theory).

In Figure 9 the color of the observatory site depends on the value of $H^{*}$ determined for the $\mathrm{T}_{\min } p d f$ 's within a $60^{\circ} \mathrm{C}$ range split into $1^{\circ} \mathrm{C}$ bins. At the 24 European stations considered the value of $H^{*}$ ranges from the maximum of 0.926 at Arkhangelsk (Russia) to the minimum of 0.684 at Stornoway Airport (Scotland). The same as abovementioned three groups of the European climate zones can be obtained by setting the two boundary thresholds of $H_{\text {Tmin }}^{*}=0.75$ and 0.85 . In a similar way the classification of climatic regions could be obtained by using the Shannon's entropy based on $\mathrm{T}_{\max }$ (see Table 3); specifically, the same three groups (though with a slightly different order of stations in a group) can be distinguished by setting the boundary thresholds $H_{\text {Tmax }}^{*}$ at 0.8 and 0.9 . Moreover, additional boundary thresholds (e.g. $H_{\text {Tmin }}^{*}=0.77$ and 0.81 or $H^{*}{ }_{\text {Tmax }}=0.81$ and 0.87 ) allow further details of classification that are not present in the classical one [10], which attributes three quarters of the sites considered to the same class $\mathrm{Cfb}$, i.e. warm zone fully humid with warm summer.

Cluster analysis provides another approach to a quantitative classification of climatic zones. It is illustrated with an application of single link cluster analysis of the correlations between the temperature $p d f$ 's. Figure 10 combines the two symmetric matrices of the correlation coefficients between all the pairs of $p d f$ 's at different stations computed for $\mathrm{T}_{\text {min }}$ (values below the diagonal) and $\mathrm{T}_{\max }$ (values above the diagonal) leaving empty the $100 \%$ diagonal. To simplify the visual perception of the pair correlations, their values are given on a color coded background.

Figure 11 displays the dendrograms resulting from single link cluster analyses of the correlation matrices for the distributions of $T_{\min }$ and $T_{\max }$ given in Figure 10. Each horizontal segment on a dendrogram represents a link between the two clusters indicated by vertical segments. The level of similarity of a link is given by the value of correlation shown on the ordinate axis (note that 

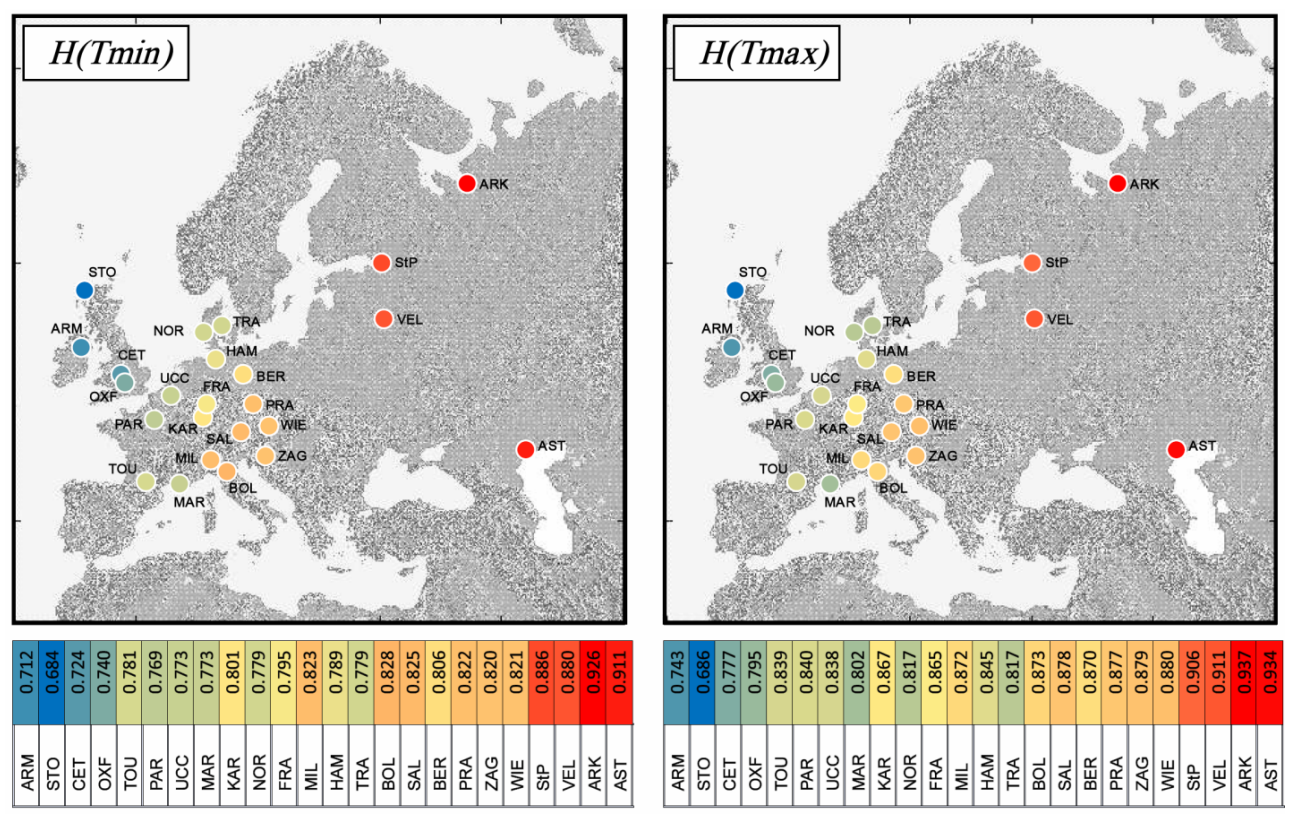

Figure 9. The normalized Shannon's entropy $H^{*}$ for $T_{\min }$ (left) and $T_{\max }$ (right) at the 24 European stations.

Table 3. The normalized Shannon's entropies $H^{*}$ computed from $T_{\min }$ and $T_{\max }$.

\begin{tabular}{|c|c|c|c|c|}
\hline \multirow{2}{*}{$\begin{array}{c}\text { Location } \\
\text { STO_Stornoway airport (UK) }\end{array}$} & \multirow{2}{*}{$\begin{array}{l}H_{\mathrm{Tmin}}^{*} \\
0.684\end{array}$} & \multirow{2}{*}{$\begin{array}{c}H_{\mathrm{Tmax}}^{*} \\
0.686\end{array}$} & \multicolumn{2}{|c|}{$\begin{array}{c}\text { Order by } \\
H_{\text {Tmin }}^{*} \text { and } H_{T \text { Tmax }}^{*}\end{array}$} \\
\hline & & & 1 & 1 \\
\hline ARM—Armagh (UK) & 0.712 & 0.743 & 2 & 2 \\
\hline CET - Central England (UK) & 0.724 & 0.777 & 3 & 3 \\
\hline OXF_-Oxford (UK) & 0.740 & 0.795 & 4 & 4 \\
\hline PAR_Paris, (France) & 0.769 & 0.840 & 5 & 10 \\
\hline MAR_-Marseille (France) & 0.773 & 0.802 & 6 & 5 \\
\hline UCC - Uccle (Belgium) & 0.773 & 0.838 & 7 & 8 \\
\hline NOR—Nordby (Denmark) & 0.779 & 0.817 & 8 & 6 \\
\hline TRA-Tranebjerg (Denmark) & 0.779 & 0.817 & 9 & 7 \\
\hline TOU_-Toulouse (France) & 0.781 & 0.839 & 10 & 9 \\
\hline HAM—Hamburg (Germany) & 0.789 & 0.845 & 11 & 11 \\
\hline FRA—Frankfurt (Germany) & 0.795 & 0.865 & 12 & 12 \\
\hline KAR — Karlsruhe (Germany) & 0.801 & 0.867 & 13 & 13 \\
\hline BER - Berlin (Germany) & 0.806 & 0.870 & 14 & 14 \\
\hline ZAG_-Zagreb Gric (Croatia) & 0.820 & 0.879 & 15 & 19 \\
\hline WIE-Wien (Austria) & 0.821 & 0.880 & 16 & 20 \\
\hline PRA—Prague (Czech Republic) & 0.822 & 0.877 & 17 & 17 \\
\hline MIL_-Milan (Italy) & 0.823 & 0.872 & 18 & 15 \\
\hline SAL—Salzburg (Austria) & 0.825 & 0.878 & 19 & 18 \\
\hline BOL—Bologna (Italy) & 0.828 & 0.873 & 20 & 16 \\
\hline VEL_-Velikie Lukie (Russia) & 0.880 & 0.911 & 21 & 22 \\
\hline StP-St Petersburg (Russia) & 0.886 & 0.906 & 22 & 21 \\
\hline AST_-Astrakhan (Russia) & 0.911 & 0.934 & 23 & 23 \\
\hline ARK_-Arkhangelsk (Russia) & 0.926 & 0.937 & 24 & 24 \\
\hline
\end{tabular}

levels increase downwards). For example, the link, above which a single cluster of the 24 stations is achieved, corresponds to a similarity level of $86.0 \%$ for $\mathrm{T}_{\min }$ (Figure 11(a)) and $78.4 \%$ for $T_{\max }$ (Figure 11(b)). For $T_{\min }$, there are four clusters at a level of similarity above $95 \%$ : these are Astrakhan (AST), Milan and Bologna (MIL, BOL), Arkhangelsk (ARK), and the remaining 20 of the 24 stations. A level above $99.7 \%$ (i.e. the maximum of the values below the diagonal in Figure 10) delivers the split into 24 classes including each single station by breaking the highest correlation link between Karlsruhe (KAR) and Frankfurt (FRA). For $\mathrm{T}_{\max }$, the level of similarity above $90 \%$ provides separation into four clusters: these are Astrakhan (AST), Arkhangelsk (ARK), St Petersburg and Velikie Lukie (StP, VEL), and the remaining 20 European stations. The level of $95 \%$ splits two additional clusters: Stornoway (STO) and Toulouse and Marseille (TOU, MAR). A level above $99.4 \%$ (i.e. the maximum of the values above the diagonal in Figure 10) is needed to break all the $\mathrm{T}_{\max }$ correlation links between the 24 stations.

\section{Conclusions}

The study of the statistical distribution of daily minimum and maximum temperatures in 24 European stations, from long series of more than a century, reveals two simple traits: a strong stability of the distributions at the different stations during the whole time span available; a strong, but ordered along a general trend, variability in space.

In the Eastern European stations, one notices an increase of about $2^{\circ} \mathrm{C}$ of the maximum temperatures in the 


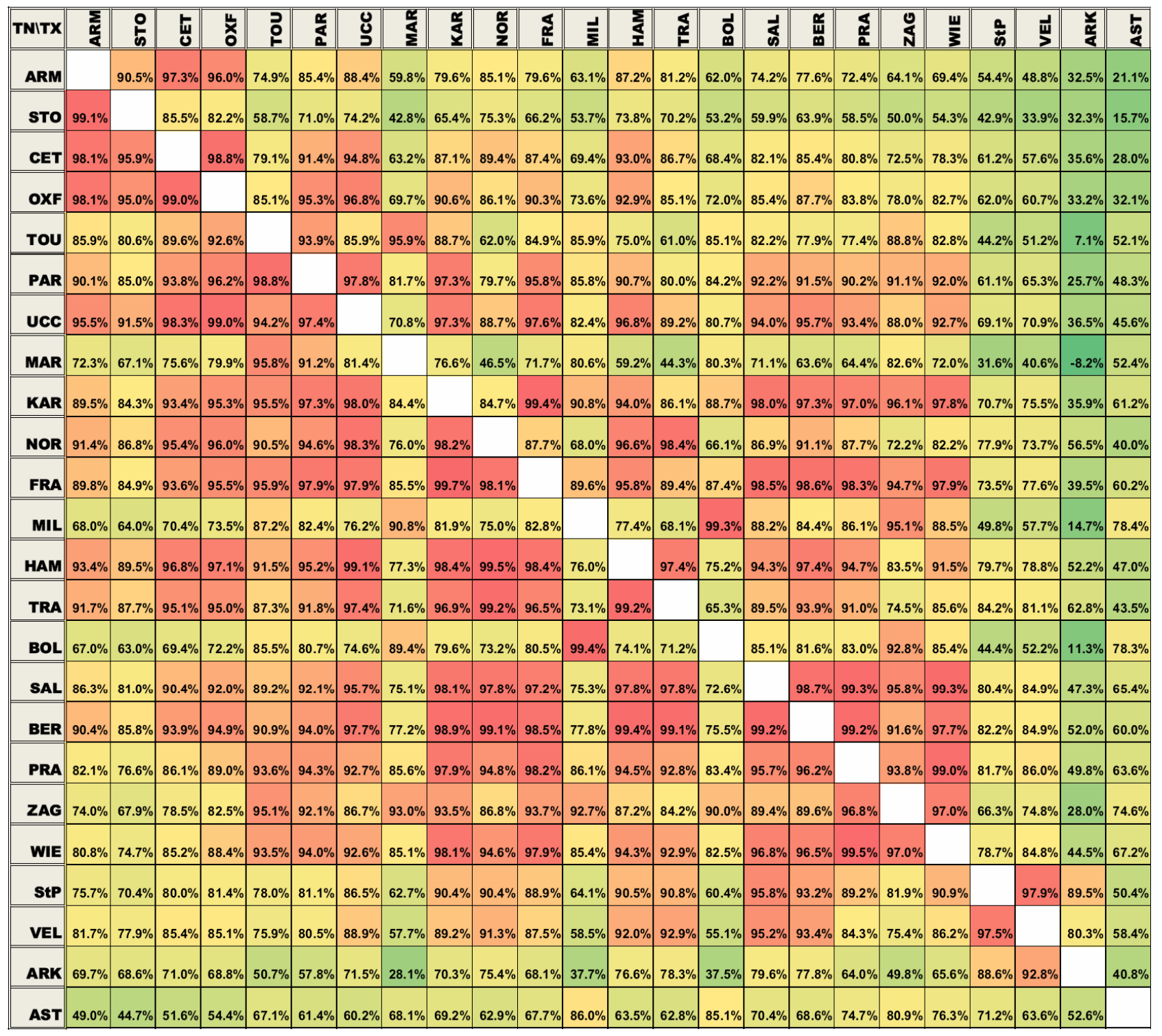

Figure 10. The correlations between the minimum daily temperature empirical density functions at different stations (below the diagonal); same for the maximum daily temperature (above the diagonal). To facilitate visual perception the correlation values are given on the color-coded background.
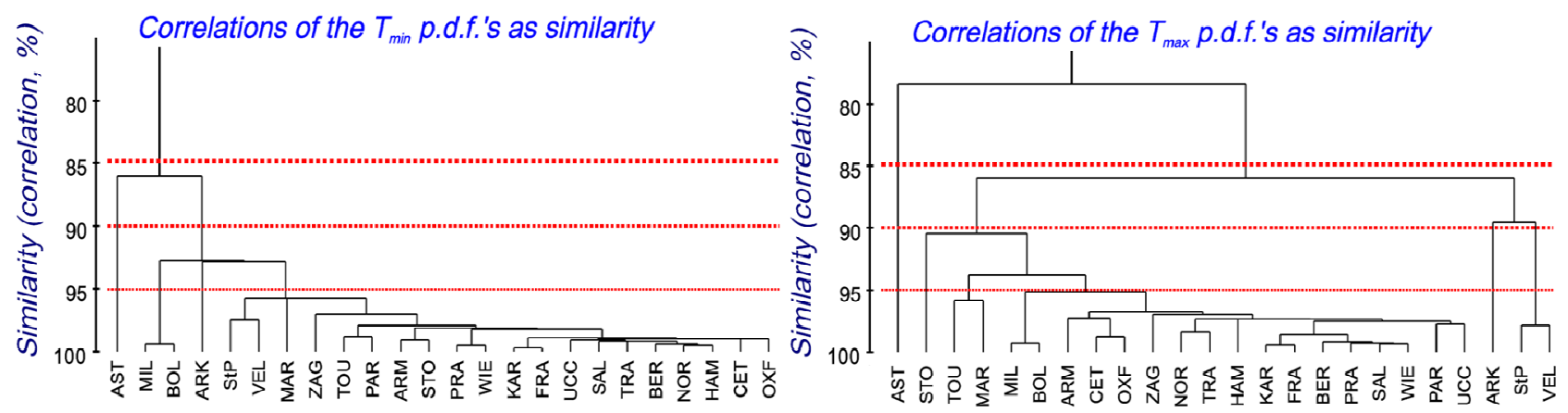

Figure 11. The results of a single-link cluster analysis based on correlation of the daily temperature density functions as the measure of similarity (upper plate for $T_{\min }$ and lower plate for $T_{\max }$ ). The arbitrary levels of $85 \%, 90 \%$, and $95 \%$ correlation marked with the dash-lines. 
last 30 years with respect to the preceding time spans, while in Central Europe there is an increase of about $1{ }^{\circ} \mathrm{C}$ of the maximum temperatures at some stations, and no discernible increase at the others. In Western Europe (British Isles, Belgium, and France) there is generally no discernible increase or decrease of the maximum and the minimum temperatures along the last century. The warming of some $0.6^{\circ} \mathrm{C}$ observed in the last decade of the 20 th century [9], is hardly visible in our analysis based of 30-year intervals. At big cities' stations (Paris, Marseille, Toulouse, Brussels) however, there is a noticeable increase of the minimum temperature, probably due to a heat island effect.

It is verified that there are several distinct stable climatic regions in Europe, which is a common knowledge; nevertheless, in each of them there is some variability in time at each station as attested by the KolmogorovSmirnov test, and larger variability from station to station. The classification in climatic zones can be made by a naked eye comparison of the $p f$ and $p d f$ curves, which contain a lot of information. It can be corroborated by quantitative analysis of those functions based on the Shannon entropy or cluster analysis, used separately or in combination. Such objective methods, as well as other tools of pattern recognition, could be employed for a more widespread and systematic classification of climatic zones.

\section{REFERENCES}

[1] A. M. G. Klein Tank, et al., "Daily Dataset of 20th-Century Surface Air Temperature and Precipitation Series for the European Climate Assessment," International Journal of Climatology, Vol. 22, 2002, pp. 1441-1453.

[2] J.-L. Le Mouël, V. Kossobokov and V. Courtillot, "A Solar Pattern in the Longest Temperature Series from Three Stations in Europe," Journal of Atmospheric and Solar-Terrestrial Physics, Vol. 72, 2010, pp. 62-76. doi:10.1016/j.jastp.2009.10.009
[3] V. Kossobokov, J.-L. Le Mouël and V. Courtillot, "A Statistically Significant Signature of Multi-Decadal Solar Activity Changes in Atmospheric Temperatures at Three European Stations," Journal of Atmospheric and SolarTerrestrial Physics, Vol. 72, 2010, pp. 595-606. doi:10.1016/j.jastp.2010.02.016

[4] D. E. Parker, T. P. Legg and C. K. Folland, "A New Daily Central England Temperature Series, 1772-1991," International Journal of Climatology, Vol. 12, 1992, pp. 317-342. doi:10.1002/joc.3370120402

[5] W. J. Burroughs, "Climate Change: A Multidisciplinary Approach," 2nd Edition, Cambridge University Press, Cambridge UK, 2007, 390 p. doi:10.1017/CBO9780511803819

[6] A. van Engelen, A. Klein Tank, G. van de Schrier and L. Klok, "Towards an Operational System for Assessing Observed Changes in Climate Extremes," European Climate Assessment \& Dataset (ECA\&D) Report 2008, Publication 224, KNMI, 2008.

[7] V. Kossobokov, J.-L. Le Mouël and V. Courtillot, "Interactive Comment on 'On Misleading Solar-Climate Relationship' by B. Legras, et al.," Climate of the Past Discussions, Vol. 6, 2010, p. C342.

http://www.clim-past-discuss.net/6/C342/2010/cpd-6-C34 2-2010.pdf

[8] R. R. McKitrick and P. J. Michaels, "Quantifying the Influence of Anthropogenic Surface Processes and Inhomogeneities on Gridded Global Climate Data," Journal of Geophysical Research, Vol. 112, 2007, Article ID: D24S09. doi:10.1029/2007JD008465

[9] J.-L. Le Mouël, E. Blanter, M. Shnirman and V. Courtillot, "Evidence for Solar Forcing in Variability of Temperatures and Pressures in Europe," Journal of Atmospheric and Solar-Terrestrial Physics, Vol. 71, 2009, pp. 1309-1321. doi:10.1016/j.jastp.2009.05.006

[10] M. Kottek, J. Grieser, C. Beck, B. Rudolf and F. Rubel, "World Map of the Köppen-Geiger Climate Classification Updated," Meteorologische Zeitschrift, Vol. 15, No. 3, 2006, pp. 259-263. doi:10.1127/0941-2948/2006/0130 